\title{
INFORMATION PROVISION OF DECISION SUPPORT SYSTEMS IN CONDITIONS OF STRUCTURAL CHANGES AND DIGITALIZATION OF THE ECONOMY
}

\author{
Yulia Vertakova ${ }^{1 *}$, Vardan Mkrtchyan², Eugene Leontyev ${ }^{1}$ \\ ${ }^{1}$ Southwest State University, Department of Regional Economics and Management, Russian Federation \\ ${ }^{2} \mathrm{HHH}$ University, Australia
}

The article was devoted to the research of methodological and practical aspects of the development and application of information support for decision-making tools to improve the competitiveness of enterprises, which together constitute a system for supporting decision-making and managing competitiveness. The algorithm for working with decision support tools in the competitiveness management process was developed and implemented, which includes the solution of the following tasks: analysis of the market situation, data collection, selection and analysis of competitor data based on BigData technology, selection of competitive pairs, modeling and forecasting of enterprises , analysis, assessment and selection of factors of influence on competitiveness, synthesis of scenarios of enterprise development, predictive modeling of dynamics of competitive indicators, the analysis of simulation results, the selection vectors factor values for the optimal development strategy, the selection of recommendations for achieving optimal values of the indicators of competitiveness, the synthesis of the recommendations of the selection rules, the provision of advice to decision-makers.

Key words: Information provision, Decision support systems, Enterprise competitiveness, Digital economy

\section{INTRODUCTION}

In conditions of digitalization of the economy, it is impossible to achieve success in business unless you plan ahead with effective development, always have information about personal prospects and opportunities, the quality and condition of the target markets, and the position of competitors on them. The effectiveness of the strategy of the enterprise, the implementation of its objectives directly depends on the quality of information on the basis of which this strategy is developing.

Business information should cover the demand for certain goods, contain the characteristics of possible competitors, as well as the conditions of the external environment. It is very important that, along with quantitative estimates, the provided information also contains qualitative characteristics. Especially valuable information of a predictive nature, giving an idea of the emerging structural changes and new trends that are of fundamental importance for the development of the strategy of a particular enterprise.

Issues of application of information systems in management and decision support systems are devoted to the works of such scientists as D.T. Bourgeois [1], G. Davis [2], A. Costa [3], K.C. Laudon [4]. The problems of structural transformations in the economy in the conditions of digitalization are reflected in the works of A.V. Babkin [5], Y.V. Vertakova [6], V.S. Mkrttchian [7], M.S. Solomatin [8], T.O. Tolstykh [6].

In accordance with the system integration theory of the enterprise, proposed by Kleiner [9], today there is a need to use modern information technologies more and more to improve the quality of decisions made in the context of providing a comprehensive strategy for managing economic systems, which is the basis of the digital economy. Experience has shown that the penetration of information technologies into all sectors of the economy both as digital assets and in the form of industrial Internet of things, etc., causes the formation of large arrays of economically significant industry and interindustry data.

Thus, the urgency of creating and maintaining an information system that ensures the prompt receipt of reliable information necessary for the successful operation of enterprises predetermined the purpose of this study.

\section{METHODOLOGY}

Informational support of managerial decsions aimed at the synthesis of information that allows to eliminate the uncertainties arising in the process of purposeful administrative activities, as well as to generate a set of possible actions to improve competitiveness. There are three groups of uncertainties. The first group includes the uncertainty about the status of the enterprise as object of management in the organizational field of the external market environment.

The second group is associated with a selection criteria of quality assessment of decisions. The third group consists of the uncertainty associated with forecasting the results of decisions.

In relation to the competitive activity of the enterprise focused operation decision maker follows. Before solving 
the problem of decision making, decision makers should be formed idea of the economic activity of the enterprise, financial and competitive status of a managed object, on the organizational field of the market, partners and competitors, about available resources and ways of influencing them. Comparing information about the current competitive state of the enterprise and its competitors in the process of benchmarking with its desired image as a leading company in the market, the decision maker evaluates the difference between the two, analyzes and selects routes of exposure, possible alternatives to eliminate this discrepancy. Further, the accepted management decision on the impact on the company, which contains information about the States of the control object and how it changes.

The main component of information security is a multidimensional data warehouse. The functioning of the repository involves the process of collecting, cleaning and standardizing data collected from various sources in the public domain on the Internet and give users access to information. The concept of information storage involves the implementation of a single information resource for a wide variety of tools. The vault is kept at the chronology: on a par with the current performance are stored historical data indicating the time to which they relate. Thus, the necessary data about the control object are collected in one place, converted to a common format, agreed, aggregated to the minimum required level of generalization. In the description of the technology filling in the information repository, there are three interrelated tasks: collection and extraction of data (data acquisition and extraction), conversion, and data cleansing (data cleaning and transformation), aggregation and loading of data in storage (data consolidation and loading).

Data collection is a process consisting in the search and transfer of data from external sources into the repository.
Under the aggregation refers to the process of calculating various aggregations of data (integral indices) and integrate them into the vault. The data cleansing process in the filling of storage include: elimination of duplicates, restore missing data, bringing data to a uniform format, removing unwanted characters, unification of data types, checking for integrity. The basic data loaded into the data warehouse include data from external and internal sources (Fig. 1).

The scheme of formation and use of information storage in DSS, shows how data is extracted from operational data sources using data integration tools (Fig. 2).

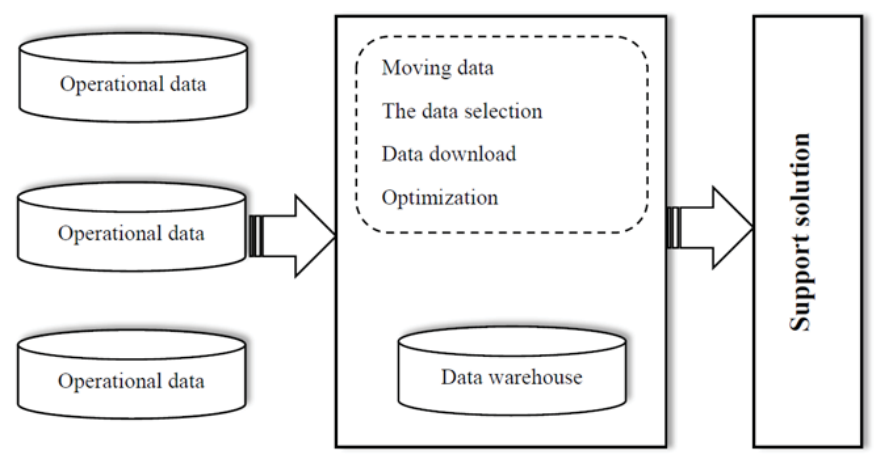

Figure 1: The data for external and internal sources

As a model of the data warehouse in the research it is proposed to use the industrial model. The industrial model is a set of predefined data models for describing business processes. Industrial models are based on the experience of many organizations and try to describe common business processes for specific industries. There are ready industrial model from IBM (financial sector, Telecom industry, health care, etc.), from EWSolutions (health, investment, law enforcement) and solutions from

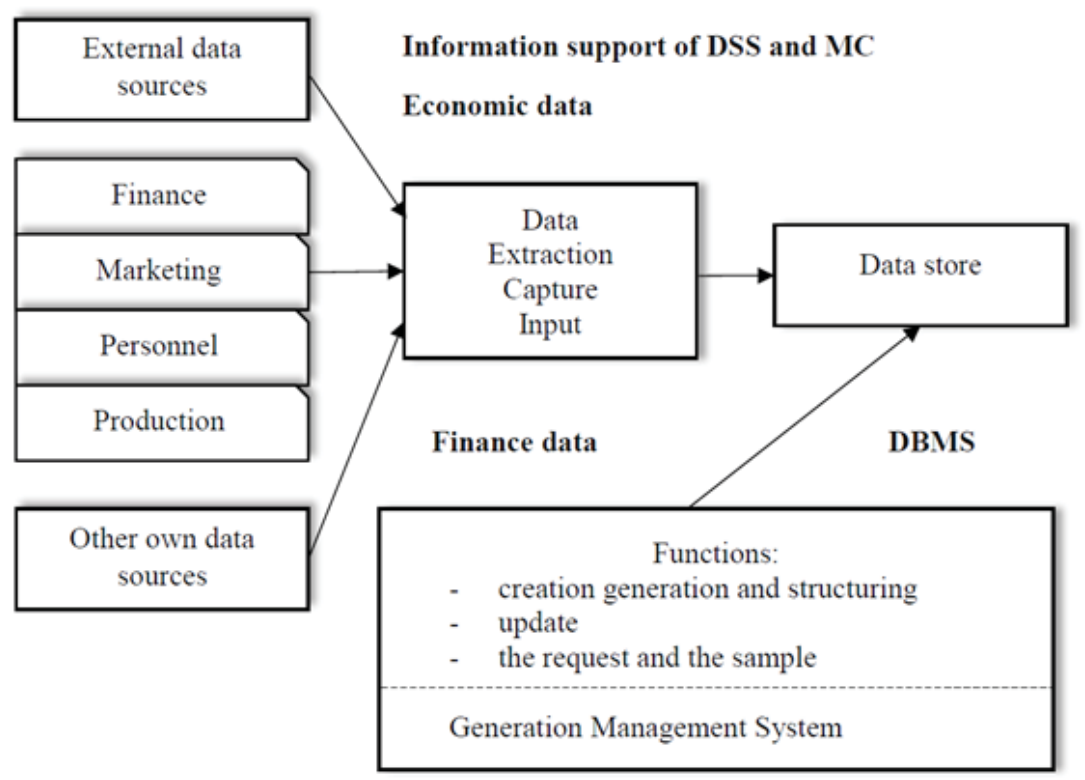

Figure 2: Diagram of integration of data in storage 
other manufacturers (Terradata, CSC). Earlier in the researches, a storage model based on the IBM Banking Data Warehouse (BDW) industrial model was implemented on the basis of tools provided by EC Leasing (Moscow). The industrial model IBM BDW consists of three data models: conceptual, logical, and physical - and the rules of transition from one model to another. The conceptual data model is a predefined set of business concepts describing different aspects of the business activities. Business concepts combined in a hierarchy with the 9 root concepts. In the process of creating the repository are selected for description of the business process concepts from the entire set, starting with the root and going down notions lower in the hierarchy. Initial data for selection of the concepts are the requirements on information structure. For each selected concept is determined by the type of its implementation: a separate relational entity, an entity attribute or attribute value. The data model obtained with the use of industrial models, describe a typical business process in a specific industry. Thereby to create the data model there is no need for a detailed study of system data sources. However, for subsystem data integration is imposed an additional burden on the transformation and harmonization of data from different sources for presentation according to the unified model.

\section{RESULTS}

To solve the problem of decision support for management of enterprise competitiveness designed database structure for solving problems of OLAP mining. In the design phase of the database has been defined, what data to store it. For information support of work tools in the database is entered from the repository the information about the current and retrospective conditions of the competing companies and their products. A fragment of a conceptual data model of the database shown in figure 3.

With entities of the model related table of the relational data. Based on the logical relational model generates a physical model for the implementation of the storage layout in the DBMS.

For the analysis and selection of performance indicators of competing companies and transfer them to the instruments of mathematical predictive modeling, data is loaded into a multidimensional showcase representing hyperstability, be used in OLAP processing. Multidimensional data is a problem for all organizations working in the business, and the complexity of the data does not necessarily depend on the size of the enterprise. As a means to work with data tables, stands OLAP tools. The basis of the data of OLAP is the notion of multidimensional cube of data in cells which are stored analyzed data. Measurement is a set of values of other data, for example, product names and names of months of the year. OLAP tools provide the ability to access, view and analyze data related to competing businesses through the data sections or Windows, which in the thesis are presented in the form of dynamic hypertable. Looking at the data and aggregates in the displays, users can analyze the information retrieved from storage. It is based on a

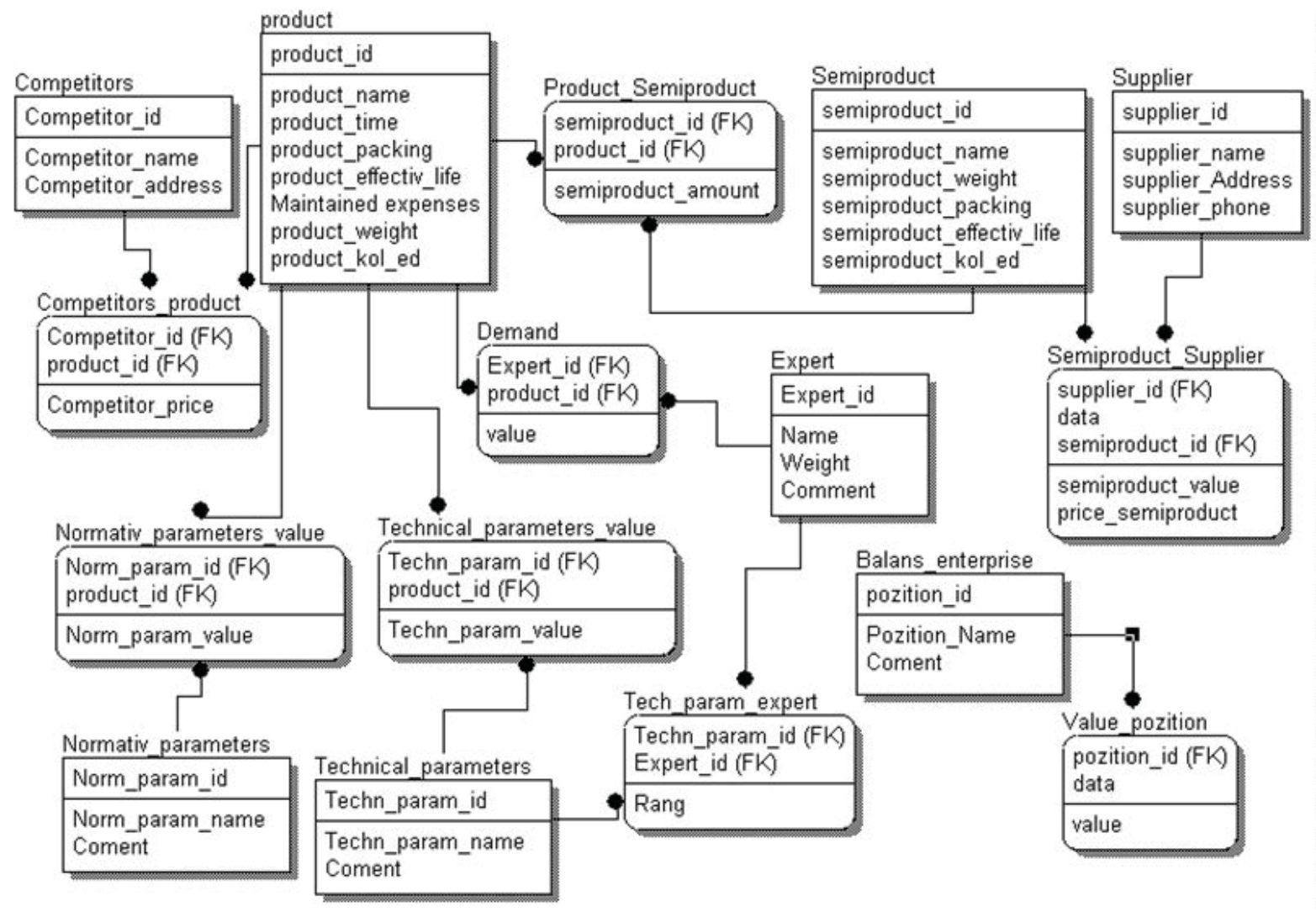

Figure 3: A fragment of the entity-relationship data model 
conceptual view as the natural look of the DM for the control object with the possibility of viewing aggregates from several independent measurements, which integrate certain data set.

Hypertable is a marketing data Mart, OLAP tool and non-standard UI element. Combines the functionality of spreadsheet analysis with a tree structure and controls to view the dynamics of changes in competitiveness indicators displayed in the cells in time. Hypertable is the imaging technology of hypercube data, the data is grouped by parameters and aggregation levels. It provides the ability to navigate in a multilevel and multidimensional tree data structure in real time. A screenshot of the data visualization module with a fragment of hypertable and schedule pricing the products presented on the figure (Fig. 4).

Feature of hypertable is that the number of rows in the table is not a static value, the strings themselves in nature and functionality are not equivalent, as some of them are aggregates. Line-aggregates are nodular and show summary information on the relevant columns, rows belonging to them at lower levels of aggregation. With aggregation lines connected button that works similar to a node tree list - allows you to hide or show the contents of the group. The number of rows of hypertable dynamic and varies depending on the state. Another key feature of hypertable is the ability to quickly view and analyze changes in variables over time (position 10 in Fig. 5). When loading data into a table, the server sends information about the values of the selected data columns for all rows and for each indicator of enterprise activity in the selected time range. The time range is determined when specifying the subset of data. Hypertable allows real-time view schedule changes any of the selected quantity over any desired period of time. Moving the slider on the timeline, you can see the changes of the values of all other cells of the table, thereby analyzing the region of interest according to schedule.

To extract data from open sources on the Internet apply intelligent software agents, integrated into ETL (Extract, Transform, Load) a subsystem of data integration in the vault. A distributed subsystem of the ETL extracts data from sources to the staging area and implements the functions for managing them in terms of structuring, cleaning, and rationing. These functions can be implemented as templates that are customized based on the target requirements for data collection of a specific type and format in the sources. Most of the documents on the activities of the enterprise is in the format of Microsoft Office (Word, Excel, PowerPoint), PDF format, and less often in HTML or XML formats. Software templates for extracting data from the documents of one format allows

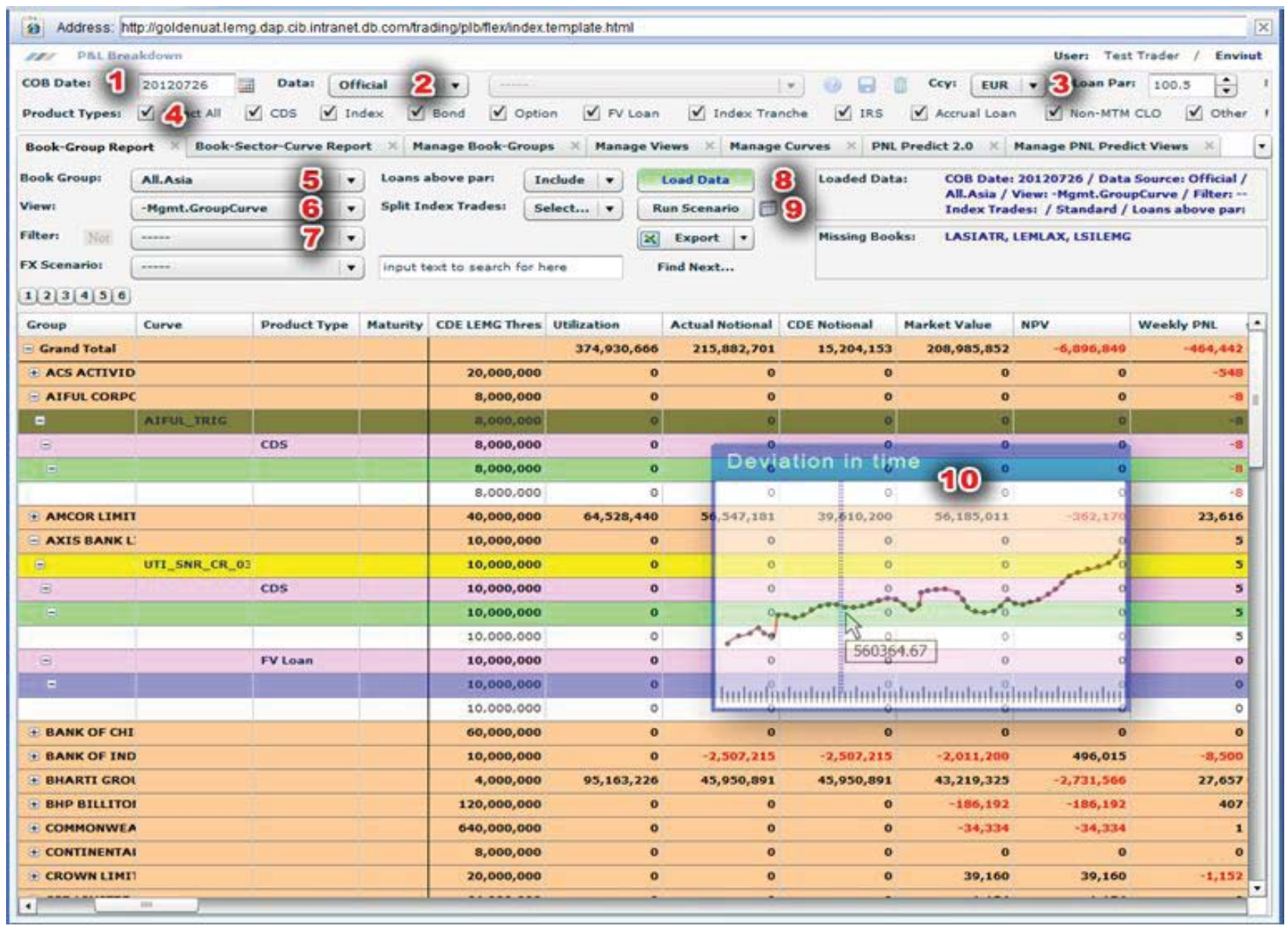

Figure 4: A fragment of hypertable to render a report on the work of banks in the process benchmarking 
to reduce the complexity of the work.

ETL subsystem consists of a set of processes that process data and mechanisms for managing progress. ETL processes work with data that is initially structured as a relational table with data about concepts. A logical concept can be a description of the characteristics of the business object (company) or an event that happened to the business object. Spreadsheet templates are also formed in advance for the enterprises of a particular type

\section{DISCUSSION}

The developed toolkit is a kind of expert intellectual decision support system.Such systems utilize expert knowledge to ensure effective decision of tasks in some subject area. In most cases, they are intended for counselling professionals (the decision maker) in solving problems that arise in semi-structured and it is difficult to formalize areas. In the information storage in such systems is stored the knowledge gained from experts, and used when the need arises. A feature of the system is the presence of the mechanism of generation of recommendations, which explains how it can be obtained solutions that contribute to the achievement of the required performance and quality for a particular company.

Expert support for decisions comes from the concept of "standard template solutions", in accordance with which the arising of a problem situation can be reduced to some homogeneous classes of solutions, i.e., to model the set of alternatives. To accomplish this, expert support is created information collection, storage and analysis of the model alternatives for specific market situations. If you are encountering a problem situation is not associated with the existing classes of the model alternatives in the repository, implement the mechanism of modeling of enterprise activity in atypical conditions, search and evaluation of possible solutions. After the implementation of the iterative process of choosing the optimal solution, predictive modeling and tuning of parameters in the original mathematical model, the solution is marked as a typical alternative, and recommendations are recorded in the information storage. Thus there is a mechanism of knowledge acquisition in intelligent system decision support.

The mode of acquisition of knowledge correspond to the stages of synthesis of mathematical models of the computing process modeling, programming in the environment of the application package Mathematica 5.1, debug programs, performance modeling and prediction, verification of the obtained results. The acquisition of knowledge requires specific skills and therefore performed the appropriate expert. To implement concrete solutions to

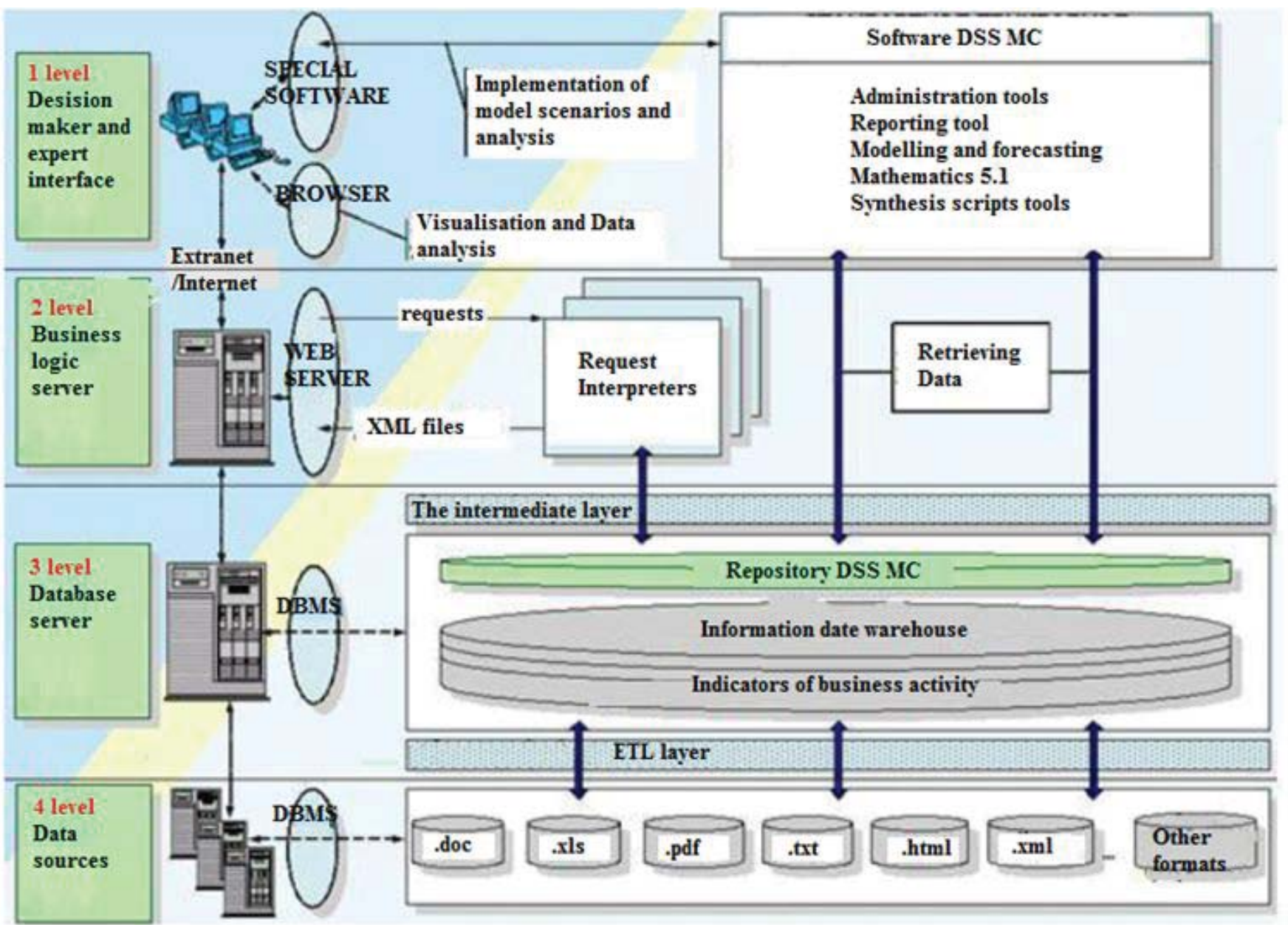

Figure 5: Main levels of architecture 
improve the competitiveness of the DM may not be an expert in programming, as it mainly works with data tables and solver expert components. Solver on the basis of data from the repository, the General data about the problem area and rules of the knowledge base generates recommendations for achieving the goal.

Instrumental complex of support of decision-making can be represented in the form of a four-tier architecture that includes: presentation tier (user interface), server level, data storage level data sources (Fig. 5). Each level uses a different set of technologies and runs a specific set of functions. The architecture of a tool set showing cross-layer information interaction between the main components. The level of data sources and databases were discussed earlier. In the presentation layer performs the main work of synthesis scenarios, analytical processing, predictive modeling, presentation of results of mining-decision makers and experts.

The user works with a standard Web browser. After au- thorization of the user on the server an opportunity to select a desired application to work, depending on the user's requirements. In response to the request, the server sends the XML page with JavaScript inserts and a client application in Adobe Flex. Next Flex-the client continues working with the server using the AMF Protocol and the HTTPS Protocol.

At the server level runs the JBoss Application Server that fulfills the client's requests and sends to the client the applications required analytical processing. The server makes a call to stored procedures and functions by means of technology of communication of Java applications and databases Java DataBase Connectivity (JDBC). Also, the server performs the necessary operations with the data, interacting with databases, and in the framework of the serialization mechanism transmits the necessary data for applications. Thus, the server performs both the role of the Web server and the application server interacts with other servers through a special API

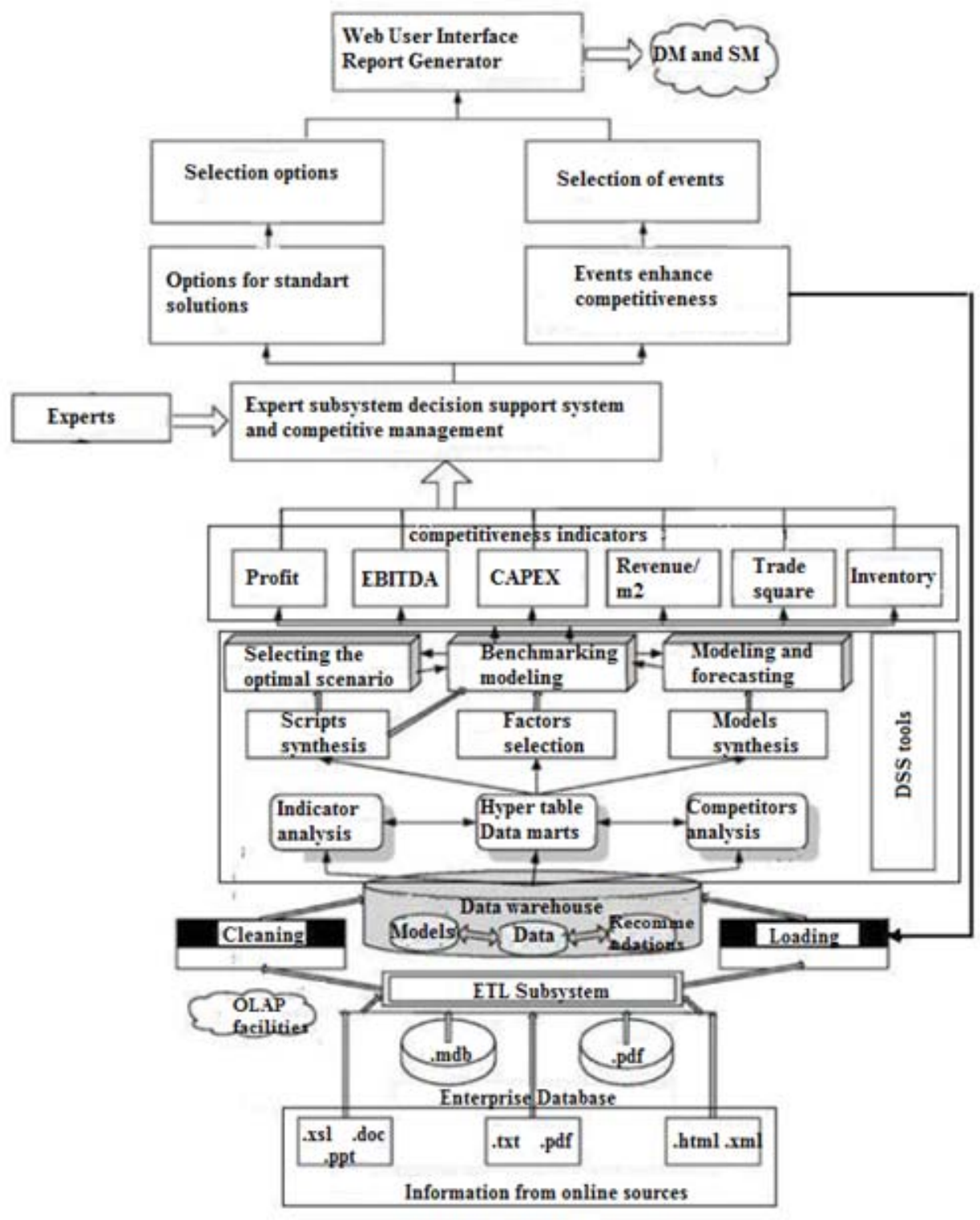

Figure 6: Architecture of a set of tools 
interfaces based on the EJB technology. Backend calculations are performed on complex algorithms that require high computational performance, such as aggregation and calculation of analytical variables. The General architecture of the Suite of tools support decision-making for management of competitiveness of enterprises with the basic operations presented in figure (Fig. 6). With the final and intermediate results of tools there are two categories of persons: makers of the decision (LPR) and decision makers (DM). If the decision maker role acts as the administrative personnel of the enterprise, as LFR needs to be qualified experts. LFR can browse the database with the collected information and problem solving modelling and research.

The main challenges addressed by the LFR are: the objective of the study and assessment of the state of the company, the task of defining order parameters to control the competitiveness of enterprises and products, the problem of evaluating the effectiveness of measures to improve competitiveness, the problem of parametric programming for the selection of optimal strategies for improving competitiveness.

\section{CONCLUSION}

The methodical and practical aspects of the development and application of information support for decision-making tools to improve the competitiveness of enterprises, which together constitute a system for supporting decision-making and managing competitiveness, are considered. The complex of tools is developed on the basis of the client-server architecture, where the JBoss Application server is chosen as the server platform.

To synthesize a mathematical model, algorithmize the modeling process, program, debug a program, perform modeling and forecasting, and verify the results, the tool environment of the Mathematica 5.1 application package was chosen.

An algorithm for working with decision support tools in the competitiveness management process has been developed and implemented, which includes the solution of the following tasks: analysis of the market situation, information gathering, selection and analysis of data on competitors based on BigData technology, selection of competitive pairs, modeling and forecasting of enterprises, analysis, assessment and selection of factors of influence on competitiveness, synthesis of scenarios of enterprise development, predictive modeling of dynamics of indicators of competitiveness analysis of modeling results, selection of vectors of factor values for optimal development strategy, selection of recommendations for achieving optimal values of competitiveness indicators, synthesis of rules for selecting recommendations, providing recommendations for decision-makers.

\section{ACKNOWLEDGEMENT}

The reported study was funded by RFBR according to the research project № 18-010-01119 «Management of digital transformation of innovation-industrial cluster as a system-forming element of the industrial digital platform: methodology, tools, practice».

\section{REFERENCES}

1. Bourgeois, David T. (2014). Information Systems for Business and Beyond. The Saylor Academy. p. 5.

2. Davis G. (1974) Management Information Systems: Conceptual Foundations, Structure, and Development. - New York: McGraw-Hill.

3. Costa, A., Ferreira, C., Bento, E., Aparicio, F. (2016). Enterprise resource planning adoption and satisfaction determinants. Computers in Human Behavior. Vol 63. pp. 659-671. DOI:10.1016/j.chb.2016.05.090

4. Laudon, Kenneth C., Laudon, Jane P. (2009). Management Information Systems: Managing the Digital Firm (11 ed.). Prentice Hall/CourseSmart. p. 164.

5. Babkin A.V., Chistyakova O.V. (2017). Tsifrovaya ekonomika i ee vliyanie na konkurentosposobnosty predprinimatelskikh struktur. Russian Journal of Entrepreneurship, 18(24). (in Russian). - DOI: 10.18334/rp.18.24.38670.

6. Tolstykh T.O., Vertakova Y.V., Shkarupeta E.V. (2018) Professional Training for Structural Economic Transformations Based on Competence Approach in the Digital Age. Mkrttchian V., Belyanina L., Handbook of Research on Students' Research Competence in Modern Educational Contexts. IGI Global. p. 518. DOI: 10.4018/978-1-5225-3485-3.ch011

7. Mkrttchian V., Bershadsky A., Finogeev A., Berezin A., Potapova I. (2018) Digital Model of Bench-Marking for Development of Competitive Advantage. Isaias P., Carvalho L.C., User Innovation and the Entrepreneurship Phenomenon in the Digital Economy. IGI Global. p. 357. DOI: 10.4018/978-1-5225-28265.ch014

8. Solomatin M.S., Saibel N.lu., Rol' tsifrovoi ekonomiki $\mathrm{v}$ razvitii gosudarstva, Institutsional'nye i infrastrukturnye aspekty razvitiia razlichnykh ekonomicheskikh sistem: sb. st. Mezhdunar. nauch.-prakt. konf., (in Russian) Vol 2, pp. 137-139.

9. Kleiner G.B. (2006) The system-integrated theory of the enterprise. Montenegrin journal of economics. № 2. pp. 21-40.

Paper submitted: 03.07.2018.

Paper accepted: 15.11.2018.

This is an open access article distributed under the CC BY-NC-ND 4.0 terms and conditions. 